\title{
A Study on Design and Development of Digital Textbooks for
}

\section{Primary School Students}

\author{
Rong $\mathrm{Fan}^{1, \mathrm{a}}$, Jin $\mathrm{CaO}^{2, \mathrm{~b}}$ \\ ${ }^{1}$ Sino-Korean Multimedia College, Shanghai University of Engineering \& Science, China \\ ${ }^{2}$ Sino-Korean Multimedia College, Shanghai University of Engineering \& Science, China \\ afanrong.sh@qq.com, ${ }^{\text {b } 584176206 @ q q . c o m}$
}

Keywords: Digital Textbooks, Design, Primary School Students, Interaction

\begin{abstract}
Traditional structure of education is mainly supported by print media. The digitalization of textbooks can turn abstract contents into representational contents, thus making it easier to understand and acquire knowledge in textbooks for primary school students. The teaching affairs will become more efficient through using of digital textbooks. It is significant to focus on user experiences and feelings when digitalizing textbooks. By designing of a digital textbook for primary school Chinese, the authors argue that in order to better realize the teaching goals of primary school Chinese lessons, designers of digital textbooks should create the situation and bring students to specific situation by intuitive videos and pictures; let the pleasant music and poetic pictures narrow the distance between students and texts, motivate the rich imagination of students, stimulate their rich emotions, broaden their spiritual space and call for beauty, thus allowing quality education to be truly implemented. The authors design textbooks
\end{abstract}

\section{Globalization and mainstreaming of digital textbooks}

Traditional structure of education is mainly supported by print media. It is very simple and boring. As human society enters the digital era in the 21st century, education also follows the digital tide inevitably. In 2006, Edinburgh University Press first published the electronic textbooks. As the globally leading education publisher, Pearson Education Group developed digital learning platform since 1994 and submitted a recommendation of digital course to California state government in 2006. Besides, it has invested \$ 20 million in developing digital teaching resources. A variety of digital teaching resources begin to develop rapidly since 2010. As many schools are equipped with complete multi-media classrooms with the access to the Internet, the digitization of various teaching resources especially the textbooks has become the important driver of modern education.

At the beginning, digital textbooks were about the digitization of book contents simply. The book contents were copied into CD or e-books so that readers could read by end reader. Education practitioners soon found that it was not teal digital teaching material. The print media teaching materials are still simple and boring. When user demand becomes diverse with the development of network, the user experience of digital teaching materials will become more and more important. The ways of presentation and communication of teaching materials have changed greatly. The boring textbooks integrate high technology, fun, art and innovation of new media age through the way of user experience design and develop into more interesting teaching applications that can interact with learners. Thus, a new age of digital teaching materials is developed. Nowadays, digital teaching materials have become the main theme of the development of digital education.

The digitized teaching materials make educational structure diverse and enrich the way, content and activities of education. First of all, teaching is changed from simple talking of teacher to exploratory learning of students. For younger students, teaching adopts more interactive and game models to cultivate their learning ability. The impact of digital textbooks on education is visual reading, interactive experience, personalized learning, multi-sensory learning, participatory learning, rich resource connection, low-cost learning and so on. Of course, digital textbooks also face a lot of 
problems. Digital textbooks should solve the reading and experience of students, the interaction between human and machine, the class knowledge teaching of teachers, teaching interaction and assessment requirements.

\section{Design principles of digital textbooks for primary school students}

The psychological characteristics of primary school students are energetic, lively and like to limitation with strong curiosity and thirst for knowledge. But they are not concentrated and tend to be distracted easily when they are studying. As children are active, they are interested in novel, interesting, specific and concrete images or stories with plots, but they cannot concentrate on abstract concepts or boring formulas for a long time.

Second, primary school students have strong self-esteem and like to be praised. The emotional control of primary school students is not as strong as adults. They will become happy immediately after they get the compliments, and they will become frustrated and desperate when people criticize them.

Third, in terms of visual aesthetics, students prefer exaggerated and funny cartoon style as well as warm colors such as red and yellow rather than dark colors.

Based on the above characteristics, during the design of digital textbooks for primary school students, warm colors should adopted in the form to meet the aesthetic preferences of students with rich colors and full picture. In addition, cute cartoon style characters can be designed to guide the contents, which is easier to make primary school students develop an overall image of the cognitive process of digital textbooks than boring splits do.

The content design should avoid boring sermon. Truth and concepts should be taught through interesting fairy tale images or stories. Teachers can interact with students by strongly interactive games and songs, which will be helpful for releasing the energy of students and efficiently keeping the attention of students. In addition, when students finish a task correctly, teachers should offer corresponding feedback and rewards. When students give a wrong answer, teachers should encourage them to improve by gentle attitude rather than offer feedback simply by the form of "failure", which may boost the confidence of students and encourage them to work harder.

\section{Digital Chinese textbooks for primary school students}

At present, digital textbooks are mostly used as an auxiliary for classroom teaching. For the primary school Chinese education, the teaching should adopt the interactive game model with digital textbooks as an auxiliary. The teaching changes from the simple talking of teachers to the exploratory learning of students, which can cultivate the independent learning ability of students more easily. Digital teaching materials can realize the interaction between primary school students and teaching materials as well as knowledge and realize the interaction between primary school students and teachers so that digital textbooks become the strong complement to classroom teaching.

The significance of digital Chinese textbooks is to develop the abstract into the specific and make it convenient for primary school students to observe, understand and master the textbooks; it simplifies the contents, improves teaching speed, saves the class hours and eases the work of teachers. Digital Chinese textbooks for primary school students are designed to optimize teaching process, meet the needs of teaching and improve teaching efficiency. The design of digital Chinese textbooks for primary school students should follow the principles as follows for this purpose:

First, comply with the laws of teaching and achieve teaching objectives. Second, express the knowledge and contents of subjects accurately

Third, it should have a wealth of expression and appeal so that students are willing to accept what they have learned and enjoy the charm of Chinese as an art. In picture, the composition, color, text, character, style, shadow, scenery and props should be arranged carefully and smartly to create a wonderful visual image; the sound should be pleasant and able to reflect the theme of lessons; the sound and picture should be harmonious and unified. 
Fourth, the designer should have a clear and rational idea and design the scientific, reasonable and interactive teaching materials with clear images and sound.

Fifth, the digital textbooks should focus on the experience of primary school students to develop the digital textbooks that meet the psychology of primary school students. User experience design is an emotional design. Through the research of user experience, the digital textbooks can comply more with the psychology of users and allow the emotional communications and interactions between users and textbooks to make it more humane, motivate the initiative of students and achieve teaching objectives.

\section{Case Studies}

\subsection{Digital book of new generation Our Choice}

The digital book of new generation Our Choice is an interactive book that contains all the methods to solve climate issues. At the beginning, way to solve all climate issues for a long interactive books. In the introduction part, the current location of user can be seen with the rotation of the earth. Anything in the book can be picked up to achieve the interactive results with users. Through the interactive map in the book, users can check where the pictures in the book come from. There are documentaries, interactive animation, information and pictures that can display the potential of wind energy in the United States.

When we blow the digital book, any excessive energy from the windmill will be converted into battery energy. As the wind becomes smaller, any excessive energy will be converted to the house and the light will never go out. This is a very interesting interaction that users can enjoy the great impact of wind energy on the environment.

\subsection{Interactive picture book The Fantastic Flying Books of Mr. Morris Lessmore}

All the book s in iPad interactive picture book The Fantastic Flying Books of Mr. Morris Lessmore can produce interactions. All the fantastic books will fly when the finger waves. It makes people smile with the music. The fantastic flying books fly from piano to the arm of Mr. Morris Lessmore from time to time. They will be open when touching the piano so that the viewers may play the piano.

The digital book is full of innovative interactive design, the real music and sound effect and immersive experience result. It allows the e-books, video animation and games to integrate reading with interaction.

\section{Design of digital textbook The World of Chinese Language of Miao Miao}

This study selects a lesson of primary school Chinese textbook of nine-year compulsory education Where is Spring as the case study of digital teaching material design and production. It aims to understand the basic condition and background of teaching, teaching materials, teachers and students, understand the experience expectations of primary school students and the framework of entire teaching material. It develops the lesson into the digital teaching material full of Chinese traditional art, fun and interaction that complies with the expectations of primary school students. In addition, it names it as The World of Chinese Language of Miao Miao according to the cartoon character.

As the learning subject, students expect digital teaching materials to be funny and interesting. Teachers expect the digital textbooks to be the manifestation form combined with pictures and texts, sound and image and the static and dynamic. While parents hope digital teaching materials can train the independent learning ability of students.

On the basis of the above research, it divides the lesson into four parts - text, knowledge, writing and exercise.

(1) Text highlights the Chinese style animation. It converts the text content into animation with dubbing, pictures and texts.

(2) Knowledge lists all the products of spring in the text and presents their meanings by videos and pictures to realize the simplification effect.. 
(3) Writing. Order of strokes is the basis of writing well. Learning to write and know characters is an important learning objective of first-year students.

(4) Exercise is the most pleasant part of The World of Chinese Language of Miao Miao. The children's song of Where is Spring with corresponding animation can deepen students' understanding of the lesson. Make students sing this song naturally to deepen their understanding of this lesson.

The digital textbook focuses on user experience. It is applicable, easy to use and interactive. For younger students, pictures, sound, music, game and other lively forms can introduce class knowledge. As a result, the distinctive and leading character of Miao Miao is designed full of childlike features. The picture composition and buttons are simple, clear and easy to use. The copy function can strengthen the interaction.

One of the goals of Chinese language lesson is to develop students' aesthetic taste and ability of traditional Chinese culture. Therefore, in terms of visual style design of digital textbooks, the combination of cartoon style and elements of traditional Chinese art is determined. For example, the horizontal scroll is the main interface with the background of traditional Chinese waterlines and rice paper shade.

The screen size of digital textbook is 1280 x 800 pixels and used in the Android system. Therefore, in terms of visual setting, the picture should look clear and concise. Lines and frames should not be adopted. The screen edge is feather in the animation video, which allows the entire screen to display the beautiful Chinese style so that students can enjoy the charm of traditional Chinese art. The concise Chinese style can highlight the interactive button elements, ensure the teaching material interface easy to use and allow students to know where to start at first sight.

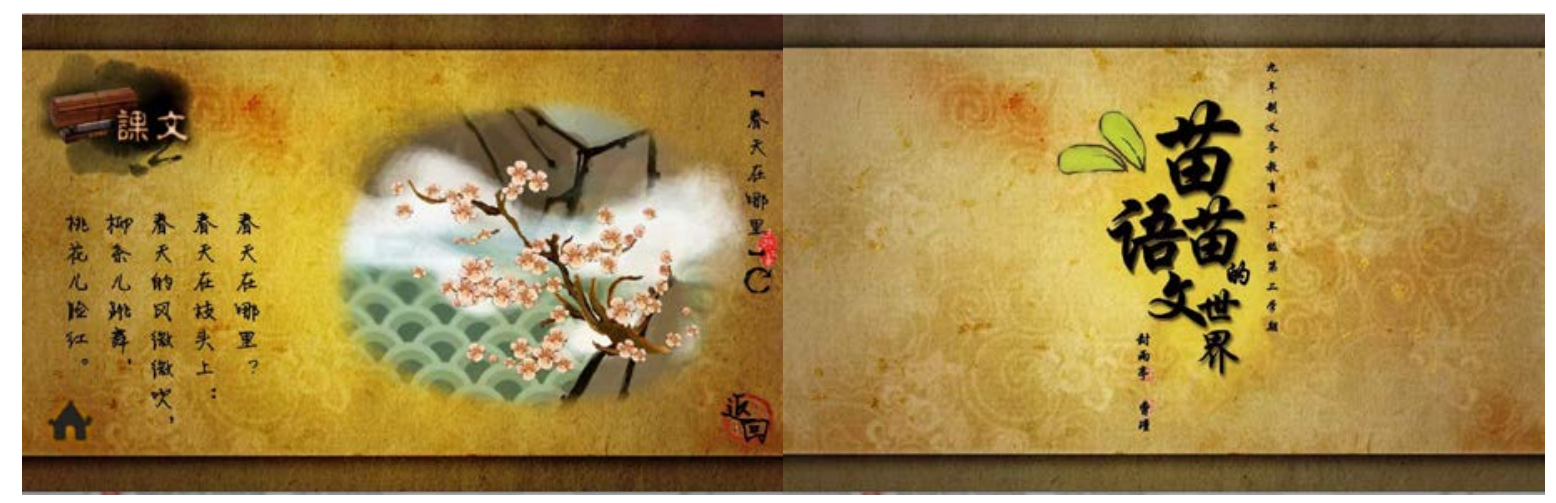

Figure 5.2 Digital Textbook Screen

Figure 5.3 Cover Text

The text is classic font. The users are primary school students, so the written classic font is adopted. Students are required to write the characters by imitating the order of strokes in writing plate. The font is standard style of handwriting. Second, we need to consider the unification of text and images. The text arrangement should follow the text style of traditional Chinese scroll from right to left and up to bottom.

In color, it breaks the tradition and improves on the basis of originally traditional Chinese style with some bright colors such as bright yellow and light green so that the characters become more obvious to attract younger students. The students can enjoy the lively atmosphere when studying. 


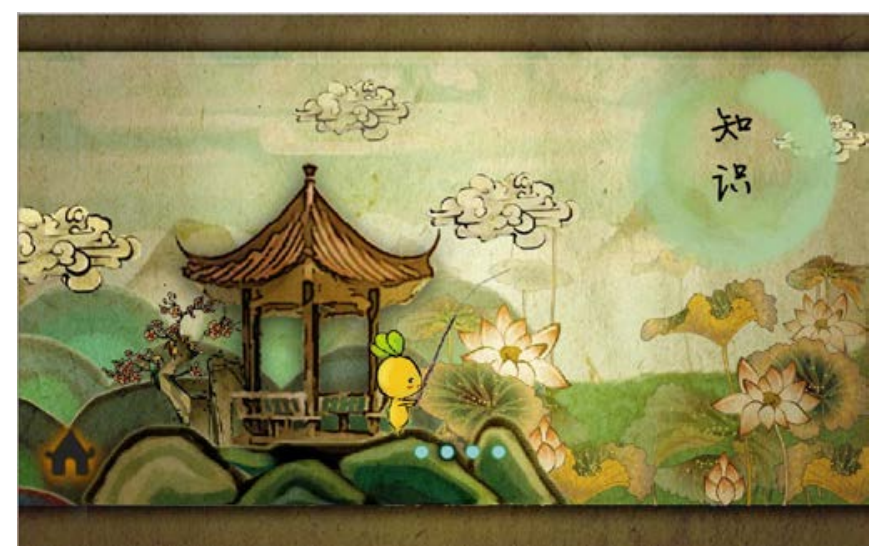

Figure 5.4 Colors of Characters

In terms of typesetting, first of all, the four parts form the entire scroll that fully reflects the traditional Chinese scroll. Second, unify the button location of tile, return and main page in various parts. The text should adopt vertical version.

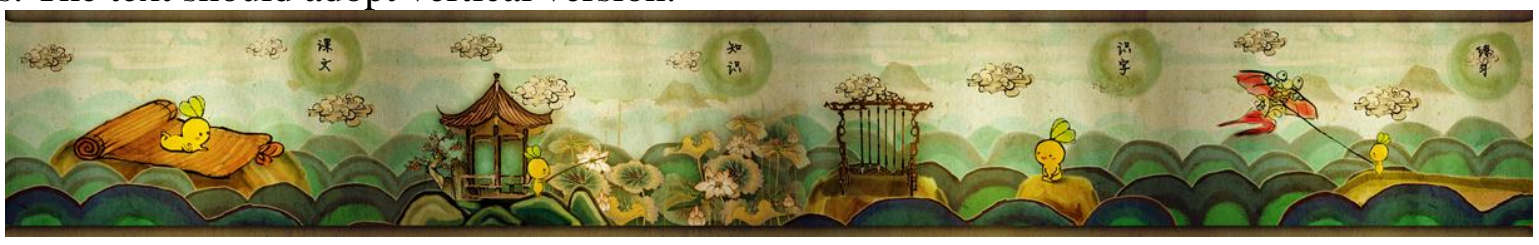

Figure 5.5 Horizontal Scroll Main Interface

User experience design principle is the most fundamental guiding thought and theoretical basis for digital textbooks, which should be followed in the process of design. User experience design should focus first-year students and provide them with more comfortable and considerate services with the same psychological guidance.

Before the design, we should conduct investigation of first-year students and get the results. First-year students are curious, active and lively and love games. Their activities and behaviors are lack of clarity. Their way of behavior and thinking is greatly dependent and imitative. Besides, they are easily distracted and attracted by irrelevant things. Their actions like writing are slow. They live bright and lively colors. Combined with the behavioral ways and psychological features of first-year students, digital teaching material have the following features:

(1) Learnability

Target users, namely the first-year students can understand the interface of the work correctly without thinking on the basis of existing knowledge and experience, which means that the interface is learnable. Adopting the reasonable metaphor like dot hints, conventional methods like button and unified location of titles and effective inspiration like guiding students to learn by characters.

(2) Consistency

In a similar scenario, the work should be consistent with the psychological characteristics of students in the first grade. It should remain consistency in visual performance, interactive behavior and operational results.

(3) Simplicity

The works should not be complex for first-year students. The less is the more. It should simplify the elements in the interface. For example, change the complex texts into icons easy to understand. The simplicity of works is reflected in three aspects: reduce visual disturbance, simplify text expression and simplify operational procedures.

(4) Fluency

Avoid interference and let primary school students clarify their primary task and goal of learning the lesson in the interface. In the lesson interface, the text is played with animation and dubbing 
fluently. Avoid the visual voice and other interference so that first-year students can remain coherence in operation.

(5) Timely Feedback

In any operational place in the interface, first-year students should get feedback timely during operation. Let the first-year students understand that operation has entered into force and the interface is still under their control. Feedback includes: the operational feedback of first-year students and the status feedback of product itself. Refer to the feedback and modify the work timely.

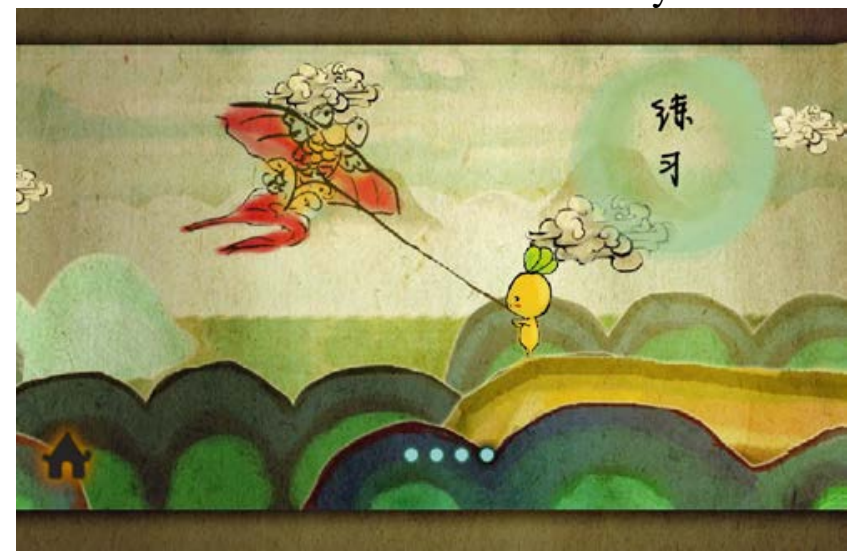

Figure 5.6 Hints of Dots in the Scroll

Finally, as the platform of the digital textbook is Android system, and the requirements of Android and Windows systems for the operation of software are different.

The digital textbook that runs smoothly in computer perhaps cannot work in Android system. Therefore, the textbook should be optimized by changing the complex slide instruction to drag instruction. In addition, in order to avoid the white screen during the loading process of Android system, the loading screen is added at the beginning to make the entire display effect of the work more fluent.

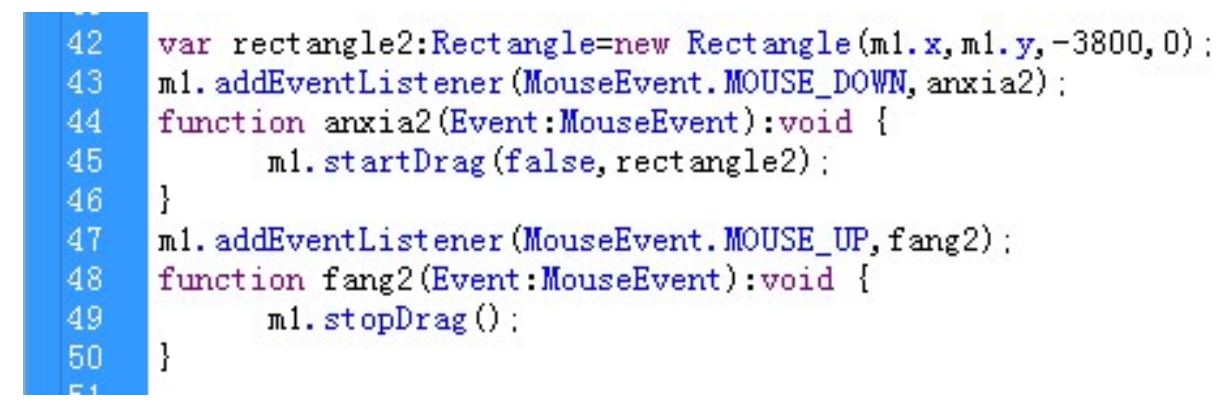

Figure 5.7 Drag Instruction 


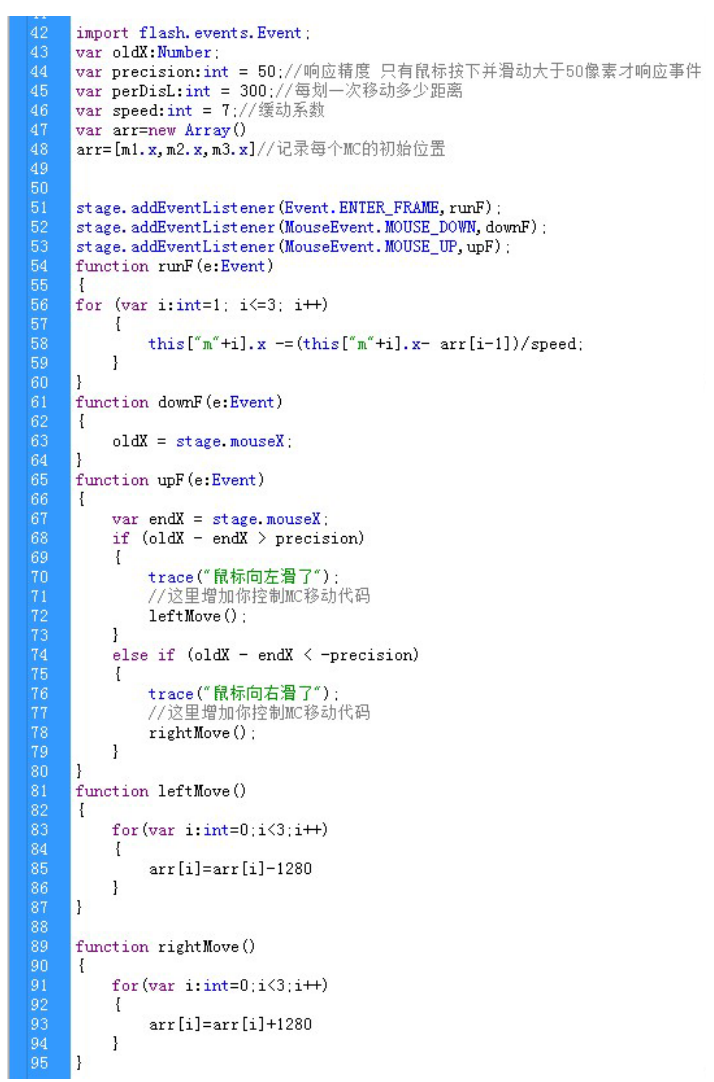

Figure 5.8 Slide Instruction

\section{Conclusions}

In the flood of digital background, digital form of traditional paper media teaching materials can give new life to the display and communication. And user xperience design with deep motions, which focus on the user experience and feelings, will make digital textbooks more charming and more popular. In order to better realize the teaching goals of primary school Chinese lessons, it is significant to design digital textbooks in line with classroom teaching that center about the user experience of primary school students and apply it in class teaching reasonably according to specific teaching situation. Create the situation and bring students to specific situation by intuitive videos and pictures; let the pleasant music and poetic pictures narrow the distance between students and texts, motivate the rich imagination of students, stimulate their rich emotions, broaden their spiritual space and call for beauty, thus allowing quality education to be truly implemented.

\section{References}

[1] Yang Jiang, Analysis to Theme Types and Basic Feature of Interactive Media Art, Journal of Beijing Film Academy, 04(2008) 12-14.

[2] Dolk Maarten, den Hertog Jaap, Gravemeijer, Koeno. Using Multimedia Cases for Educating the Primary School Mathematics Teacher Educator: A Design Study. International Journal of Educational Research, 37(2002), 161-78

[3] Na Zhao, Telling Stories by Way of Interactive Entertainment, Humor and the Humorist, 02(2011)32-33.

[4] Weidong Chen, Xindong Ye, Jiping Zhang. Research on Interaction Modus and Characteristics in Future Classroom, E-Education Research, 08(2011)101-103.

[5] Information on http://www.docin.com/p-269222135.html

[6] Information on http://blog.sina.com.cn/s/blog_4c4e8dc901009ujg.html 